\title{
INTERAÇÃO COMPETITIVA DE Brachiaria brizantha E B. plantaginea sob Doses Reduzidas de Fluazifop-P-Butil, Aplicadas em DIFERENTES ÉPOCAS ${ }^{1}$
}

\author{
Competitive Interaction Between Brachiaria brizantha and B. plantaginea Under Reduced \\ Doses of Fluazifop-P-Butyl and Different Application Times
}

SILVA, A.C. ${ }^{2}$, FREITAS, R.S. ${ }^{2}$, FERREIRA, L.R. ${ }^{3}$, SILVA, A.A. ${ }^{3}$ e BELO, A.F. ${ }^{2}$

\begin{abstract}
RESUMO - Objetivou-se neste trabalho avaliar a interação competitiva de Brachiaria brizantha e B. plantaginea sob doses reduzidas de fluazifop-p-butil, aplicadas em diferentes épocas. O delineamento experimental adotado foi o de blocos casualizados, com quatro repetições, seguindo o arranjo fatorial $6 \times 3$, com seis doses de fluazifop-p-butil $(7,5 ; 12,5 ; 18,75 ; 31,25$; 43,75 e 62,5 $\left.\mathrm{g} \mathrm{ha}^{-1}\right)$, aplicadas em três épocas $(14,24$ e 34 dias após a emergência das plantas - DAE), mais uma testemunha sem herbicida. A maior dose utilizada correspondeu a $33 \%$ da dose recomendada para a cultura da soja $\left(187,5 \mathrm{~g} \mathrm{ha}^{-1}\right)$. A avaliação dos tratamentos foi realizada aos $53 \mathrm{DAE}$ das espécies. As plantas foram desmembradas em folhas e colmos, determinando-se a biomassa seca das partes. Foram também avaliados a área foliar, o número e o comprimento dos colmos. B. plantaginea foi mais suscetivel ao fluazifop-p-butil do que $B$. brizantha. A dose de $25 \mathrm{~g} \mathrm{ha}^{-1}$ do herbicida, aplicada aos $14 \mathrm{DAE}$, permitiu máximo acúmulo de biomassa seca de $B$. brizantha e controlou satisfatoriamente $B$. plantaginea. Aplicando-se nessa mesma época a dose de $62,5 \mathrm{~g} \mathrm{ha}^{-1}$ de fluazifop-p-butil, as duas espécies foram controladas. Quanto ao efeito de épocas de aplicação, quando utilizadas doses reduzidas, que não visam o controle pleno das espécies, plantas mais jovens de $B$. brizantha e B. plantaginea apresentaram melhor capacidade de recuperação.
\end{abstract}

Palavras-chave: braquiária, gramíneas, competição, fluazifop-p-butil.

\begin{abstract}
The objective of this work was to evaluate the competitive interaction between Brachiaria brizantha and B. plantaginea under reduced rates of fluazifop- $p$-butyl and different application timings. The experimental design was a randomized complete block, with four replications, arranged in a $6 \times 3$ factorial, consisting of six doses of fluazifop-p-butyl $(7,5 ; 12,5$; 18,$75 ; 31,25 ; 43,75$ and 62,5 $\left.\mathrm{g} \mathrm{ha}^{-1}\right)$, applied in three times $(14,24$ and 34 days after plant emergence-DAE) and a control without herbicide. The highest dose applied corresponded to 33\% of the recommended dose for soybean $\left(187,5 \mathrm{~g} \mathrm{ha}^{-1}\right)$. The evaluation of the treatments was accomplished 53 DAE. The plants were grouped into leaves and stems, and their dry biomass obtained. Leaf area, stem number and stem length of both species were determined. B. plantaginea was more susceptible to fluazifop-p-butyl than B. brizantha. It was observed that $25 \mathrm{~g} \mathrm{ha}^{-1}$ of fluazifop-p-butyl, applied at 14 DAE allowed maximum B. brizantha dry biomass accumulation and satisfactory control of B. plantaginea. In this application timing the dose of $62.5 \mathrm{~g} \mathrm{ha}^{-1}$ controlled both species. Regarding application timing, when treated with reduced doses not intended to achieve full species control, young plants of $\boldsymbol{B}$. brizantha and $\boldsymbol{B}$. Plantaginea presented better recovery ability.
\end{abstract}

Key words: Brachiaria, grasses, competition, fluazifop-p-butyl.

Recebido para publicação em 23.9.2004 e na forma revisada em 21.4.2005.

2 Pós-graduandos do curso de Fitotecnia da Universidade Federal de Viçosa-UFV, 36571-000 Viçosa-MG < andreia@vicosa.ufv.br>;

${ }^{3}$ Prof. Adjunto do Dep. de Fitotecnia da UFV. 


\section{INTRODUÇÃO}

A integração agricultura-pecuária tem sido proposta com o intuito de tornar essas atividades mais rentáveis e competitivas. Culturas anuais em cultivos seqüenciais ou simultâneos com forrageiras são utilizadas visando a recuperação mais sustentável de pastagens degradadas (Carvalho et al., 1990; Portes et al., 2000). Dentro dessa linha de pesquisa, trabalhos têm sido desenvolvidos com a finalidade de otimizar a formação de pastagens, utilizando doses reduzidas de herbicidas para viabilizar o consórcio entre culturas anuais e espécies forrageiras (Jakelaitis et al., 2004; Silva et al., 2004).

A redução da dose do herbicida visa paralisar ou reduzir o crescimento da forrageira, diminuindo sua interferência na cultura anual. Todavia, um dos desafios dessa tecnologia é a presença de outras espécies gramíneas infestantes, como $B$. plantaginea, que podem exercer grande interferência no desenvolvimento inicial da cultura e da forrageira.

A espécie $B$. plantaginea tem sido apontada como uma das gramíneas mais problemáticas em cultivos de soja no Brasil (Martins, 1994; Pires et al., 2001; Fleck et al., 2002). Silva et al. (2004) observaram que a presença desta espécie quando se cultivou soja e $B$. brizantha em sistema consorciado, utilizando doses reduzidas de fluazifop-p-butil, comprometeu o pleno estabelecimento da forrageira. Características como rápido crescimento inicial e dossel vigoroso tornam $B$. plantaginea altamente competitiva com $B$. brizantha, que, por sua vez, apresenta lento crescimento inicial e dossel menos vigoroso no início do seu desenvolvimento.

Diversos trabalhos demonstram que o estádio de desenvolvimento das espécies daninhas interfere na eficácia dos herbicidas (Askew et al., 2000; Johnson \& Hoverstad, 2002). Com relação às gramíneas, Smeda $\&$ Putnam (1990) verificaram que a eficácia do fluazifop-p-butil foi reduzida quando o número de folhas das gramineas aumentou de 3-5 para 7. Assim como o estádio de desenvolvimento, as espécies gramíneas apresentam suscetibilidade diferenciada a um mesmo ingrediente ativo, ou seja, é possivel que determinada dose possa ser seletiva a $B$. brizantha e não-seletiva a B. plantaginea, viabilizando o controle desta espécie daninha pelo manejo da dose e da época de aplicação do herbicida, preservando $B$. brizantha. Estes mesmos autores relataram que as espécies gramineas Setaria viridis, Digitaria sanguinalis, Setaria lutescens, Setaria faberi e Echinochloa crusgalli apresentaram suscetibilidade diferenciada em relação ao fluazifop-p-butil, fato também constatado por Friesen \& Wall (1991) para Setaria viridis, Avena fatua, trigo e cevada.

Objetivou-se neste trabalho avaliar os efeitos de doses reduzidas de fluazifop-p-butil, aplicadas em diferentes épocas, na interação competitiva de $B$. brizantha e B. plantaginea.

\section{MATERIAL E MÉTODOS}

O experimento foi realizado em casa de vegetação, no período de abril a junho de 2004, utilizando plantas de $B$. brizantha cv. MG5 e $B$. plantaginea semeadas diretamente em vasos contendo 3,0 L de substrato (Argissolo Vermelho-Amarelo câmbico, acrescido de $4 \mathrm{~kg} \mathrm{~m}^{-3}$ do fertilizante 4-14-8). A unidade experimental foi representada por um vaso contendo uma planta de $B$. brizantha e uma de B. plantaginea.

O delineamento experimental adotado foi o de blocos casualizados, com quatro repetições e arranjo fatorial $6 \times 3$, sendo seis doses de fluazifop-p-butil $(7,5 ; 12,5 ; 18,75 ; 31,25 ; 43,75$ e $\left.62,5 \mathrm{~g} \mathrm{ha}^{-1}\right)$, aplicadas em três épocas $(14,24$ e 34 dias após a emergência das plantas DAE), e uma testemunha sem herbicida. As doses utilizadas variaram de 4,0 a $33,3 \%$ da dose recomendada para a cultura da soja $\left(187,5 \mathrm{~g} \mathrm{ha}^{-1}\right)$. A aplicação do herbicida foi feita com pulverizador costal de precisão, equipado com barra de dois bicos TT110.02, espaçados de $0,5 \mathrm{~m}$, à pressão constante de $3,0 \mathrm{kgf} \mathrm{cm}^{-2}$, aplicando-se o equivalente a $200 \mathrm{~L} \mathrm{ha}^{-1} \mathrm{de}$ calda.

A emergência das espécies ocorreu quatro dias após a semeadura, sendo as avaliações dos tratamentos realizadas aos 53 DAE. As plantas foram desmembradas em folhas e colmos, eliminando-se as folhas mortas. Foram determinados o número e o comprimento dos colmos de ambas as espécies. A biomassa seca do material vegetal foi obtida secando-o em estufa de circulação forçada de ar a 
$70{ }^{\circ} \mathrm{C} \pm 2{ }^{\circ} \mathrm{C}$, até atingir peso constante. A área foliar das plantas foi determinada por meio de um medidor de área foliar Li-cor, modelo LI-3100.

Os dados obtidos foram submetidos à análise de variância e os modelos de regressão escolhidos com base na significância dos coeficientes de regressão, no coeficiente de determinação e no fenômeno em estudo. Os modelos adotados foram o de Gaussian $\mathrm{Y}=\mathrm{a}^{*} \exp \left(-0,5\left(\left(\mathrm{x}-\mathrm{x}_{0}\right) / \mathrm{b}\right)^{2}\right.$ e o Logístico $\mathrm{Y}=\mathrm{a} /$ $\left(1+\left(\mathrm{x} / \mathrm{x}_{0}\right)^{\mathrm{b}}\right)$. Para comparar as médias dos tratamentos com a da testemunha foi utilizado o teste de Dunnett a 5\% de probabilidade.

\section{RESULTADOS E DISCUSSÃO}

Houve interação de doses e épocas de aplicação do fluazifop-p-butil para todas as características avaliadas de $B$. brizantha e $B$. plantaginea, indicando que a época de aplicação interferiu na eficácia das doses.

Quando o fluazifop-p-butil foi aplicado aos 14 e 24 DAE (Figura 1-A), observou-se acréscimo de biomassa seca da parte aérea de $B$. brizantha nas doses intermediárias. A Figura 1-B evidencia que esse acréscimo está associado ao decréscimo de biomassa seca da parte aérea de $B$. plantaginea, que se mostrou mais suscetivel ao herbicida, concordando com os trabalhos desenvolvidos por Smeda \& Putnam (1990) e Friesen \& Wall (1991), os quais observaram diferenças de suscetibilidade ao herbicida fluazifop-p-butil entre espécies gramíneas.

As doses mais baixas $\left(7,5\right.$ e $\left.12,5 \mathrm{~g} \mathrm{ha}^{-1}\right)$ do fluazifop-p-butil, aplicadas aos 14 e 24 DAE, não apresentaram eficácia no controle de $B$. plantaginea, a qual apresentou acúmulo máximo de biomassa seca da parte aérea, não diferindo da testemunha sem herbicida. Todavia, o acúmulo de biomassa seca foi inferior quando essas doses foram aplicadas aos $34 \mathrm{DAE}$ e nos demais tratamentos. Em relação a $B$. brizantha, a dose de $31,25 \mathrm{~g}^{\text {ha }}{ }^{-1}$ de fluazifopp-butil, aplicada aos $14 \mathrm{DAE}$, foi superior à da testemunha sem herbicida, confirmando a hipótese de que existe uma dose de fluazifopp-butil que favorece $B$. brizantha em competição com B. plantaginea.

Aos 14 e 24 DAE, verifica-se, pelo parâmetro " $x_{0}$ " da equação de regressão (dose correspondente ao ponto de saturação da variável em estudo) apresentada na Figura 1-A, que os pontos de máximo acúmulo de biomassa seca de $B$. brizantha representam as doses em que $B$. plantaginea é praticamente controlada pelo herbicida (Figura 1-B). Esses dados demonstram que nas doses inferiores a 25 e $23 \mathrm{~g} \mathrm{ha}^{-1}$ de fluazifop-p-butil, aplicadas aos 14 e $24 \mathrm{DAE}$, respectivamente, $B$. brizantha é mais suscetível ao efeito da competição com B. plantaginea do que ao herbicida. Entretanto, as doses mais altas causam efeitos negativos sobre $B$. brizantha, mesmo sem a presença de B. plantaginea.

Quando o herbicida foi aplicado aos $34 \mathrm{DAE}$, observou-se efeito diferenciado para $B$. brizantha, ou seja, máximo acúmulo de biomassa seca nas menores doses, o que é explicado pelo melhor controle de $B$. plantaginea nessa época de aplicação, reduzindo a competição e incrementando a biomassa de B. brizantha.

A aplicação tardia foi mais eficaz no controle das espécies (Figuras 1 e 2). Considerando as doses geralmente recomendadas, a literatura relata que, na aplicação tardia do fluazifop-p-butil, o controle tende a ser menos eficaz, uma vez que as plantas estão mais desenvolvidas e, portanto, com maior capacidade de recuperação (Smeda \& Putnam, 1990). Contudo, neste estudo observou-se que, quando se trabalha com doses reduzidas do fluazifop-p-butil, as quais não visam o controle pleno das gramíneas, as plantas mais jovens apresentam maior capacidade de recuperação. Todavia, a diferença de resposta entre épocas foi decrescendo à medida que se utilizaram doses maiores. Aplicando-se $62,5 \mathrm{~g} \mathrm{ha}^{-1} \mathrm{de}$ fluazifop-p-butil (33\% da dose recomendada), as épocas se equivaleram.

Uma possivel causa para esse efeito seria o fato de que, na aplicação precoce, as plantas apresentavam área foliar muito reduzida, portanto, com menor interceptação do herbicida, o que poderia ser determinante na eficácia do produto, visto que se trabalhou com doses extremamente reduzidas. Outro ponto a ser considerado é que, na aplicação precoce, as plantas tiveram intervalo de tempo maior para se recuperar. A avaliação final foi efetuada aos 53 DAE, ou seja, aos 39, 29 e 19 dias após as aplicações. Em situação de campo, a aplicação

Planta Daninha, Viçosa-MG, v. 23, n. 1, p. 79-84, 2005 
efetuada aos 34 dias da emergência da cultura é seguida pelo seu fechamento (ex. da soja); assim, a planta está sob o efeito do herbicida e do sombreamento, reduzindo a capacidade de retomar o crescimento, ao passo que, na aplicação precoce, a planta tem um intervalo de tempo maior para retomar seu crescimento.
Em ensaio de campo, Silva et al. (2004) verificaram que doses reduzidas de fluazifopp-butil aplicadas aos 21 DAE da soja consorciada com $B$. brizantha foram menos eficazes no controle da forrageira que aplicadas aos $28 \mathrm{DAE}$, corroborando os resultados deste trabalho.
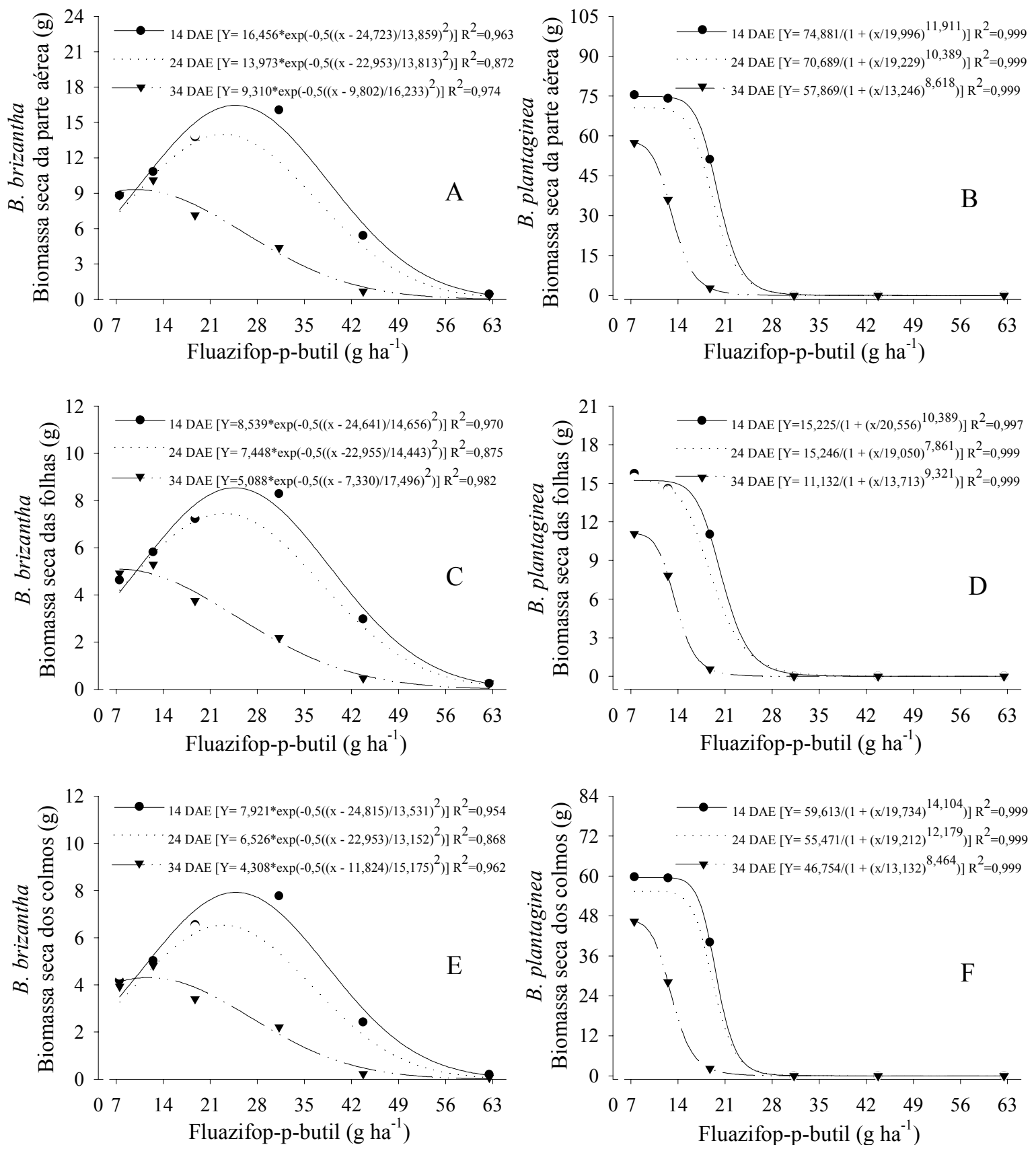

Figura 1 - Biomassa seca da parte aérea (A,B), das folhas (C,D) e dos colmos (E,F) de B. brizantha e B. plantaginea, respectivamente, em função de doses de fluazifop-p-butil, aplicadas em diferentes épocas. 
Verificou-se que as folhas (Figura 1-C e D) e os colmos (Figura 1-E e F) das espécies apresentaram comportamento semelhante em relação aos tratamentos. Nas menores doses, a biomassa seca das folhas de B. plantaginea chegou a $15,22 \mathrm{~g}$ contra $4,10 \mathrm{~g}$ de $B$. brizantha. Esses valores foram mais discrepantes quanto à biomassa seca dos colmos, cujos valores foram de 59,61 e 3,49 g, respectivamente, refletindo o vigor e rápido acúmulo de biomassa de $B$. plantaginea, a qual exerceu alta competição sobre $B$. brizantha, demonstrando, assim, ser melhor competidora.
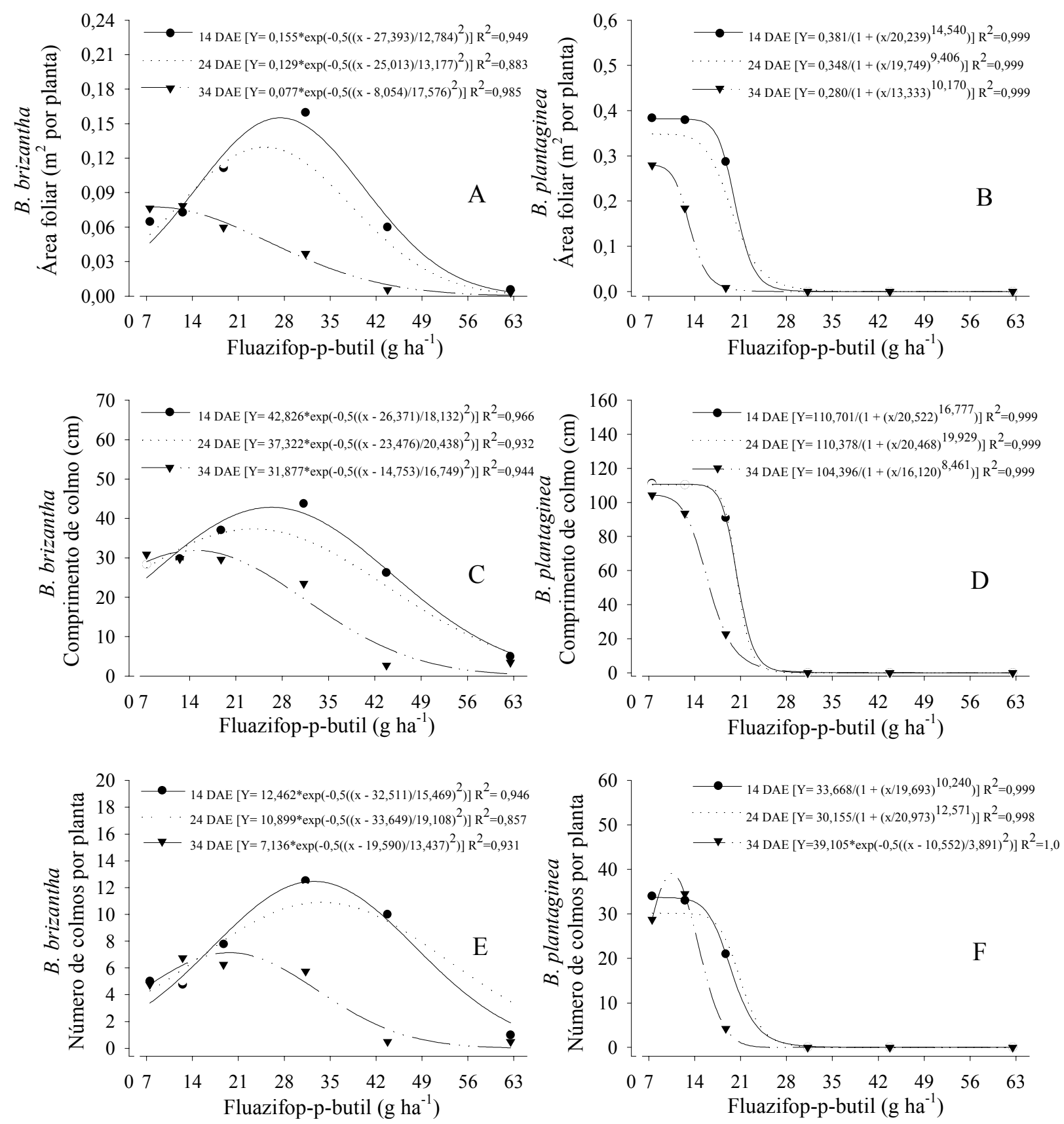

Figura 2 - Área foliar (A,B), comprimento (C,D) e número de colmos (E,F) de B. brizantha e B. plantaginea, respectivamente, em função de doses de fluazifop-p-butil, aplicadas em diferentes épocas. 
Radosevich \& Holt (1984) definem índice de área foliar como um meio de investigar possiveis vantagens competitivas entre espécies no campo. O crescimento mais vigoroso de $B$. plantaginea fica notório quando se compara a área foliar das espécies (Figura 2-A e B), as quais seguiram o mesmo padrão de resposta da biomassa seca em relação aos tratamentos. A área foliar máxima obtida por $B$. brizantha foi de $0,155 \mathrm{~m}^{2}\left(27,4 \mathrm{~g} \mathrm{ha}^{-1}\right.$ de fluazifop-p-butil), e a testemunha sem herbicida apresentou área foliar de apenas $0,077 \mathrm{~m}^{2}$, ou seja, $50 \%$ menor, demonstrando que $B$. brizantha foi favorecida pelo herbicida em relação a $B$. plantaginea. A máxima área foliar de $B$. plantaginea foi de 0,380 $\mathrm{m}^{2}$, não diferindo da testemunha nas doses de 7,5 e $12,5 \mathrm{~g} \mathrm{ha}^{-1}$ de fluazifop-p-butil, aplicadas aos 14 e $24 \mathrm{DAE}$, sendo inferior nos demais tratamentos.

Observa-se na Figura 2-C e D que o comprimento dos colmos foi menor para ambas as espécies quando o herbicida foi aplicado mais tardiamente; $B$. plantaginea apresentou colmos muito maiores que os de $B$. brizantha nas menores doses.

Na Figura 2-E e F, verifica-se que o número de colmos apresentou a mesma tendência dos demais tratamentos. Todavia, observa-se pela Figura 2-F que as doses mais baixas de fluazifop-p-butil, aplicadas tardiamente, promoveram aumento no número de colmos de B. plantaginea. Observou-se, em estudos preliminares (dados não publicados), que doses reduzidas do fluazifop-p-butil ocasionam quebra da dominância apical das gramíneas, ocorrendo maior perfilhamento das plantas.

Os resultados permitem concluir que a espécie $B$. plantaginea é mais suscetivel ao herbicida fluazifop-p-butil que $B$. brizantha. A dose de $25 \mathrm{~g}$ ha $^{-1}$ de fluazifop-p-butil, aplicada aos $14 \mathrm{DAE}$, permitiu máximo acúmulo de biomassa seca de $B$. brizantha e controlou satisfatoriamente $B$. plantaginea. Com 62,5 $\mathrm{g}^{\text {ha-1 }}{ }^{-1}$ e fluazifop-p-butil, ambas as espécies foram controladas. Quando são utilizadas doses reduzidas, as quais não visam o controle pleno das espécies, plantas mais jovens de $B$. brizantha e $B$. plantaginea apresentam melhor capacidade de recuperação.

\section{LITERATURA CITADA}

ASKEW, S. D.; SHAW, D. R.; STREET, J. E. Graminicide application timing influences red rice (Oryza sativa) control and seedhead reduction in soybean (Glycine max). Weed Technol., v. 14, n. 1, p. 176-181, 2000.

CARVALHO, S. I. C. et al. Recuperação de pastagens degradadas de Brachiaria decumbens cv. Basilisk na região dos Cerrados. Pasturas Tropic., v. 12, n. 2, p. 24-28, 1990.

FLECK, N. G. et al. Período crítico para controle de Brachiaria plantaginea em função de épocas de semeadura da soja após dessecação da cobertura vegetal. Planta Daninha, v. 20, n. 1, p. 53-62, 2002.

FRIESEN, G. H.; WALL, D. A. Effect of application factors on efficacy on fluazifop-p-butyl in flax. Weed Technol., v. 5 , n. 3 , p. 504-508, 1991.

JAKELAITIS, A. et al. Controle de plantas daninhas, crescimento e produção de milho e Brachiaria brizantha cultivados em consórcio. B. Inf. SBCPD, v. 10, p. 231-232, 2004. (Suplemento).

JOHNSON, G. A.; HOVERSTAD, T. R. Effect of row spacing and herbicide application timing on weed control and grain yield in corn (Zea mays). Weed Technol., v. 16, n. 3, p. 548-553, 2002.

MARTINS, D. Interferência de capim-marmelada na cultura da soja. Planta Daninha, v. 12, n. 2, p. 93-99, 1994.

PIRES, J. L. F. et al. Redução na dose do herbicida aplicado em pós-emergência associada a espaçamento reduzido da cultura de soja para controle de Brachiaria plantaginea.

Planta Daninha, v. 19, n. 3, p. 337-343, 2001.

PORTES, T. A. et al. Análise do crescimento de uma cultivar de braquiária em cultivo solteiro e consorciado com cereais. Pesq. Agropec. Bras., v. 35, n. 7, p. 1349-1358, 2000.

RADOSEVICH, S. R.; HOLT, J. S. Weed ecology: implications for vegetations management. New York: John Willey \& Sons, 1984. 265 p.

SILVA, A. C. et al. Efeitos de doses reduzidas de fluazifopp-butil no consórcio entre soja e Brachiaria brizantha. Planta Daninha, v. 22, n. 3, p. 429-435, 2004.

SMEDA, R. J.; PUTNAM, A. R. Influence of temperature, rainfall, grass species, and growth stage on efficacy of fluazifop-p-butil. Weed Technol., v. 4, n. 2, p. 349-355, 1990. 